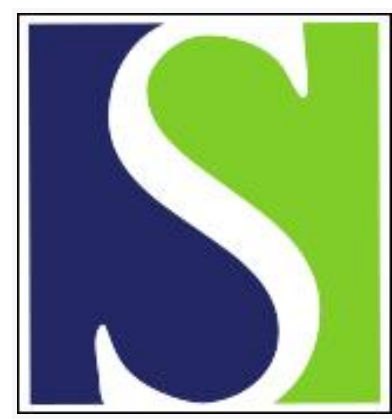

Scand J Work Environ Health 2014;40(5):531-538

https://doi.org/10.5271/sjweh.3443

Published online: 21 Jun 2014, Issue date: 01 Sep 2014

Differential cross-sectional associations of work- and leisure-time sitting, with cardiorespiratory and muscular fitness among working adults

by Saidj M, Jørgensen T, Jacobsen RK, Linneberg A, Aadahl M

In this cross-sectional population-based study among working adult men and women, we found that work- and leisure-time sitting were differentially associated with cardiorespiratory and muscular fitness. The way sitting time is accrued may be important, and caution is urged when labeling all sedentary behaviors as equally detrimental for cardiorespiratory and muscular health.

Affiliation: Research Centre for Prevention and Health, Glostrup University Hospital, Nordre Ringvej 57, Building 84-85, DK-2600 Glostrup, Denmark. madina.saidj@regionh.dk

Key terms: cardiorespiratory; cardiorespiratory fitness; cross-sectional study; leisure time; leisure-time sitting; muscle strength; muscular fitness; occupational sitting; physical fitness; sedentary lifestyle; sedentary work; work-time sitting; working adult

This article in PubMed: www.ncbi.nlm.nih.gov/pubmed/24951961 


\title{
Differential cross-sectional associations of work- and leisure-time sitting, with cardiorespiratory and muscular fitness among working adults
}

\author{
by Madina Saidj, MSc, ${ }^{1}$ Torben Jørgensen, DMSci, 1, 2, 3 Rikke K Jacobsen, MSc, ${ }^{1}$ Allan Linneberg, MD, \\ PhD, ${ }^{1,2,4}$ Mette Aadahl, MPh, PhD ${ }^{1}$
}

\begin{abstract}
Saidj M, Jørgensen T, Jacobsen RK, Linneberg A, Aadahl M. Differential cross-sectional associations of work- and leisure-time sitting, with cardiorespiratory and muscular fitness among working adults. Scand J Work Environ Health. 2014;40(5):531-538. doi:10.5271/sjweh.3443
\end{abstract}

Objectives Sedentary behavior is increasingly recognized as a risk factor for cardiovascular and metabolic morbidity and mortality. Recent studies suggest that sitting during work and leisure time may affect markers of cardiometabolic health, differently. However, little is known about associations' between sitting time and cardiorespiratory and muscular fitness among adults. The aim of the present study was to examine associations between work- and leisure-time sitting, and key markers of cardiorespiratory and muscular fitness among working adults.

Methods Working adults ( $\mathrm{N}=2544$ ) aged 18-69 from Health2006, a Danish population-based study, were included in this cross-sectional study. Sitting time during work and leisure time along with sociodemographic and behavioral covariates, including physical activity, were self-reported. Participants underwent a health examination with assessment of cardiorespiratory fitness (step test estimated $\mathrm{VO}_{2} \mathrm{Max}$, systolic and diastolic blood pressure) and muscular fitness (handgrip strength, lower limb extension power). Associations were explored by linear regression.

Results Leisure-time sitting time was significantly $(\mathrm{P}<0.05)$ and inversely associated with $\mathrm{VO}_{2} \mathrm{Max}$, systolic blood pressure and handgrip strength among adults $<50$ years. There were no significant associations between sitting time at work and any of the markers of cardiorespiratory and muscular fitness.

Conclusion Work- and leisure-time sitting were differentially associated with cardiorespiratory and muscular fitness among working adults. This suggests that the domain in which sitting time is accrued should be considered when further investigating the relationship between sedentary behaviors and various healthy outcomes. In particular, caution should be exercised when labeling occupational sitting a danger per se for health.

Key terms muscle strength; occupational sitting; physical fitness; sedentary lifestyle; sedentary work.

Traditionally, focus on workplace sitting has emanated primarily from musculoskeletal medicine with an ergonomics perspective and emphasis on musculoskeletal pain and disorders $(1,2)$. Research has shown that time spent being sedentary (operationalized as sitting time) may also have detrimental effects on cardiometabolic biomarkers, type 2 diabetes, cardiovascular disease (CVD), and premature mortality (3-5). Prolonged sitting appears to be a risk factor even among individuals who engage in recommended levels of daily moderate-to-vigorous physical activity (MVPA) (6). Hence, sedentary behavior is increasingly recognized as a distinct type of behavior and risk factor for multiple cardiometabolic health outcomes $(6,7)$.

Cardiorespiratory and muscular fitness reflect current physical performance status. Cardiorespiratory fitness is the capacity of the cardiovascular and pulmonary systems to supply oxygen during sustained exercise. Poor cardiorespiratory fitness is a strong risk factor for morbidity and premature mortality, especially of cardiovascular origin, among adults (8). Muscular fitness, ie, muscular power, strength and endurance, is related to musculoskeletal morbidity, eg, low-back pain, but is also considered important for

1 Research Centre for Prevention and Health, the Capital Region of Denmark, Glostrup, Denmark.

2 Faculty of Health and Medical Sciences, University of Copenhagen, Copenhagen, Denmark.

3 Faculty of Medicine, University of Aalborg, Aalborg, Denmark.

4 Department of Clinical Experimental Research, Glostrup University Hospital, Glostrup, Denmark.

Corresponding to: Madina Saidj, Research Centre for Prevention and Health, Glostrup University Hospital, Nordre Ringvej 57, Building 84-85, DK-2600 Glostrup, Denmark. [E-mail: madina.saidj@regionh.dk] 
hormonal and substrate metabolism, particularly for insulin sensitivity of active skeletal muscles (9), and is related to premature mortality among adults (10). Adverse associations of sedentary behaviors have been identified with cardiorespiratory and muscular fitness among children and young adults $(11,12)$, and with muscular fitness among the elderly (13). Interestingly, leisure-time TV viewing was negatively associated with muscular fitness, whereas Internet usage was positively associated with muscular strength (13).

In line with the opposing findings of occupational and leisure-time physical activity on global health and sickness absence (17), we and others have previously suggested that sitting time at work may be less deleterious to cardiometabolic health than sitting during leisure time (14-16). Due to the increasing prevalence of sedentary occupations, working adults are more exposed to the potentially detrimental risks of prolonged sedentary behavior. Thus, the possible difference between sitting at work and during leisure time should be further explored in relation to other health outcomes.

The overall aim of the study was to investigate how sedentary behavior is associated with key markers of cardiorespiratory and muscular fitness in a sample of working adults, and how domains of sitting and work influence these associations.

\section{Methods}

\section{Ethics statement}

The Ethics Committee of Copenhagen County approved this study (KA-20060011). All participants gave their written informed consent prior to their inclusion in the study.

\section{Design and participants}

Participants comprised all working adults from a Danish cross-sectional population-based study called Health2006, which was conducted June 2006-2008 at the Research Centre for Prevention and Health. The participants in Health2006 were drawn as a random sample from the background population aged 18-69 years and living in the South-Western part of the greater Copenhagen area. A total of 3471 persons entered the study (participation rate: 44.7\%). All participants completed questionnaires on health, lifestyle, and sociodemographic factors, and underwent a health examination with assessment of anthropometric measures, and cardiorespiratory and muscular fitness. Details of the enrolment and examination procedures are described elsewhere (18).

\section{Sitting time}

Sitting time was assessed using sedentary items from the Physical Activity Scale 2 (PAS2) (19), a revised version of the Physical Activity Scale (PAS) (20) validated against diaries, accelerometer and $\mathrm{VO}_{2} \operatorname{Max}(20,21)$. We used cognitive interviewing to test PAS2 and assess construct validity, indicating superior structure to PAS (19). In PAS2, participants report hours and minutes spent in (i) usual weekly leisure time and work physical activity of light, moderate, and vigorous intensity and (ii) daily sedentary pursuits during leisure time and work. Leisure-time sitting (hours/day) was derived as a continuous variable from the question: "In your leisure time, how many hours and minutes per day do you spend watching TV, sitting quietly, reading, and listening to music or the like?". Work-time sitting (hours/day) was derived as a continuous variable from the question: "During work, how many hours and minutes per day do you engage in sedentary work?".

\section{Cardiorespiratory and muscular fitness}

Cardiorespiratory fitness included estimated $\mathrm{VO}_{2} \mathrm{Max}$ $(\mathrm{ml} / \mathrm{kg} / \mathrm{min})$ and systolic and diastolic blood pressure (BP) (mmHg). $\mathrm{VO}_{2} \mathrm{Max}$ was measured by the performance-based progressive Danish step test (www.healthcalc.com/fitness-tests/the-danish-step-test), validated against a Wattmax test (22). Systolic and diastolic BP were each measured twice with a mercury sphygmomanometer after 5 minutes of rest in a lying position, and the mean of the two measurements was considered for the analysis.

Muscular fitness included hand-grip strength (HGS) $(\mathrm{kg})$ and lower-limb extension power (LEP) (watt $/ \mathrm{kg}$ ). HGS was measured in the dominant hand using a Jamar dynamometer (Sammons Preston Rolyan, Chicago, IL, USA). The best of three measurements was considered the maximum HGS (23). High inter-rater and test-retest reliability have been demonstrated for these procedures (24). Maximum single LEP was measured using a Nottingham Leg Extensor Power Rig (Medical Engineering Unit, University of Nottingham Medical School, Nottingham, UK). The maximum speed of the flywheel was used to calculate the average power of the lower-limb extensor muscles. Participants familiarized themselves with the procedure in two test-trials, and were given verbal encouragement during measurements. The right lower limb was measured unless the participant had a knee or ankle problem, in which case the left-lower limb was measured (25). High test-retest reliability of the LEP measurement has been reported (26).

Health examinations were conducted from 07.00 12.30 hours. Participants were asked to fast as of midnight prior to the examination. 


\section{Covariates}

Sociodemographic covariates and occupation type. Sociodemographic covariates included sex, age [19-29, 30-39, 40-49, 50-59, 60-72 years, dichotomized in $<50 / \geq 50$ years since muscle strength is age-reliant (26, 27 )], education (basic=up to high school, $\leq 1$ year of vocational training, short $=1-3$ years of vocational training or equivalent, and long-term $=>3$ years vocational training, ie, academic degree), and occupation type [categorized as desk-based (jobs mainly requiring sitting, little walking), light walking (eg, light industrial work, kitchen job, teaching), some physical effort (eg, construction work, service delivery, moving boxes), and hard physical effort (eg, dredging and concrete work], based on self-report.

Behavioral covariates. Behavioral covariates included self-reported smoking (categorized by current and noncurrent smoker), alcohol consumption [based on Danish recommended maximum drinking limits $(\leq 14$ and $\leq 7$ units per week for men and women, respectively), diet [obtained from a 48-item food-frequency questionnaire (28) and classified into three group of diets: imprudent (ie, low fruit/vegetables/fish and high fat intake), moderately prudent (ie, medium fruit/vegetables/fish/fat intake) and prudent (ie, high fruit/vegetables/fish and low fat intake)]. This diet classification has been validated as a measure of dietary quality in a Danish population (28). Self-reported weekly leisure-time moderate-to-vigorous physical activity (MVPA) (hours/week) and occupational physical activity (hours/week) were derived from the PAS2 questionnaire (19). Participants were classified by current recommendations for Danish adults to engage in $\geq 30$ minutes of MVPA per day (categorized by $<3.5$ and $\geq 3.5$ hours/week). Occupational physical activity was derived as a continuous variable from the question "During work, how many hours and minutes per day do you engage in hard physical work activities (eg, heavy lifting or stair climbing)?". A proxy of occupational stress was derived from the question "Do you have influence on your work?" with 5-point categories from "To a very little extent" to "To a very great extent".

Anthropometric covariates. Anthropometric covariates included height and waist circumference. Height was measured without shoes to the nearest centimeter. Waist circumference was measured at midway level between the lowest rib and the iliac crest. All measurements followed a standardized protocol and the same four trained nurses and laboratory technicians carried out all measurements.

\section{Study sample}

From a total sample of 3471 Health2006 participants, 2544 were included in the analyses. Reasons for exclu- sion of participants were not working $(\mathrm{N}=833,24 \%)$ and missing data on sitting time $(\mathrm{N}=76,2 \%)$ and work status $(\mathrm{N}=18,0.5 \%)$. Work status included all full- or part-time and voluntary work, irrespective of working hours. One participant was excluded because of mobility limitations. LEP was included in examinations after study start and is measured in a subsample $(\mathrm{N}=319)$.

\section{Statistical analysis}

Associations between work- and leisure-time sitting and each cardiorespiratory and muscular fitness measure were explored in multiple linear regression models. Models included the covariates sex, age, height, education, smoking, alcohol consumption, diet, MVPA, and occupational physical activity. Only participants with complete data were included in analyses. Restricted linear splines (10, 50, 90 percentiles) were tested in all analyses to account for non-linear associations of sitting time. Fit was compared using an F-test. When necessary, the fitness markers were log transformed and results were back transformed.

Participants in anti-hypertensive treatment $(\mathrm{N}=174)$ were excluded from systolic and diastolic BP analyses. BP models were repeated with adjustment for waist circumference to consider potential confounding by adiposity and with a proxy for occupational stress to account for a possible effect of job stress on BP. Seasonal variation (defined by the month of health examination), and adjustment for the respective other sitting domain was also investigated to account for possible interrelation between work- and leisure-time sitting.

No consistent sex-interactions were found hence models are presented for men and women combined. Results for HGS are presented for participants $<50$ and $\geq 50$ years because of a significant interaction with age.

P-values $<0.05$ were considered statistically significant. Statistical analyses were performed with software package SAS 9.3 (SAS Institute, Cary, NC, USA).

\section{Results}

Baseline characteristics by domain of sitting time, covariates, and cardiorespiratory and muscular fitness are presented in table 1. Mean daily hours of sitting were 3.1 [standard deviation (SD) 1.4] during leisure-time, and 4.1 (SD 2.7) during work.

The results of regression analyses are presented in Figure $1(\mathrm{~A}-\mathrm{E}) . \mathrm{VO}_{2} \mathrm{Max}$ (figure 1A) was significantly, detrimentally associated with leisure-time sitting $(\mathrm{P}<0.05)$, but not associated with work-time sitting. Systolic BP (figure 1B) was significantly detrimentally associated with leisure-time sitting $(\mathrm{P}<0.05)$, but not with work-time 
Table 1. Baseline characteristics of the study population by sex, sitting time, covariates and cardio-respiratory and muscular fitness. [BP=blood pressure; freq=frequency; HGS=handgrip strength; LEP= lower-limb extension power; MVPA=moderate-to-vigorous physical activity; SD=standard deviation].

\begin{tabular}{|c|c|c|c|c|c|c|c|c|c|c|c|c|}
\hline & $\begin{array}{l}\text { All } \\
\text { (N) }\end{array}$ & Mean & SD & $\begin{array}{l}\text { Freq } \\
(\%)\end{array}$ & $\begin{array}{l}\text { Men } \\
\text { (N) }\end{array}$ & Mean & SD & $\begin{array}{l}\text { Freq } \\
(\%)\end{array}$ & $\begin{array}{l}\text { Women } \\
\text { (N) }\end{array}$ & Mean & SD & $\begin{array}{c}\text { Freq } \\
(\%)\end{array}$ \\
\hline Leisure sitting (hours/day) & 2544 & 3.1 & 1.4 & & 1174 & 3.2 & 1.4 & & 1370 & 2.9 & 1.3 & \\
\hline Work sitting (hours/day) & 2544 & 4.1 & 2.7 & & 1174 & 4.1 & 2.8 & & 1370 & 4.1 & 2.5 & \\
\hline Age (years) & 2544 & & & & 1174 & & & & 1370 & & & \\
\hline $19-29$ & & & & 9.7 & & & & 7.8 & & & & 11.3 \\
\hline $30-39$ & & & & 17.4 & & & & 17.2 & & & & 17.5 \\
\hline $40-49$ & & & & 31.6 & & & & 30.3 & & & & 32.7 \\
\hline $50-59$ & & & & 29.7 & & & & 29.7 & & & & 29.8 \\
\hline $60-72$ & & & & 11.5 & & & & 14.9 & & & & 8.6 \\
\hline Education (years) & 2488 & & & & 1149 & & & & 1339 & & & \\
\hline$\leq 1$ & & & & 16.6 & & & & 16.2 & & & & 17.0 \\
\hline $1-3$ & & & & 34.7 & & & & 20.4 & & & & 47.0 \\
\hline$>3$ & & & & 48.6 & & & & 63.4 & & & & 36.0 \\
\hline Occupation type & 2530 & & & & 1169 & & & & 1361 & & & \\
\hline Desk-based & & & & 40.7 & & & & 38.7 & & & & 42.5 \\
\hline Light walking & & & & 39.5 & & & & 34.0 & & & & 44.2 \\
\hline Some physical effort & & & & 16.7 & & & & 22.4 & & & & 11.8 \\
\hline Hard physical effort & & & & 3.1 & & & & 4.9 & & & & 1.5 \\
\hline Smoking & 2534 & & & & 1173 & & & & 1361 & & & \\
\hline Current smoker & & & & 21.5 & & & & 20.5 & & & & 22.5 \\
\hline Not current smoker & & & & 78.5 & & & & 79.5 & & & & 77.5 \\
\hline Alcohol consumption, (drinks/week) a & 2482 & & & & 1164 & & & & 1318 & & & \\
\hline$\leq$ Drinking limits & & & & 72.0 & & & & 71.0 & & & & 72.9 \\
\hline$>$ Drinking limits & & & & 27.9 & & & & 28.9 & & & & 27.1 \\
\hline Diet & 2526 & & & & 1171 & & & & 1355 & & & \\
\hline Prudent & & & & 24.3 & & & & 16.4 & & & & 31.3 \\
\hline Moderately prudent & & & & 69.2 & & & & 73.7 & & & & 65.4 \\
\hline Imprudent & & & & 6.4 & & & & 9.9 & & & & 3.4 \\
\hline MVPA (hours/week) b & 2544 & & & & 1174 & & & & 1370 & & & \\
\hline$<3.5$ & & & & 51.1 & & & & 46.2 & & & & 55.3 \\
\hline$\geq 3.5$ & & & & 48.9 & & & & 53.8 & & & & 44.7 \\
\hline Occupational physical activity (hours/week) & 2543 & 0.6 & 1.2 & & 1174 & 0.8 & 1.5 & & 1369 & 0.4 & 0.9 & \\
\hline Height $(\mathrm{cm})$ & 2542 & 172.9 & 9.2 & & 1174 & 180.0 & 6.6 & & 1368 & 166.8 & 6.2 & \\
\hline Waist circumference $(\mathrm{cm})$ & 2542 & 87.9 & 13.6 & & 1174 & 94.4 & 11.9 & & 1370 & 82.4 & 12.5 & \\
\hline Estimated $\mathrm{VO}_{2} \mathrm{Max}(\mathrm{ml} / \mathrm{kg} / \mathrm{min})$ & 2367 & 33.5 & 10.7 & & 1090 & 34.8 & 9.4 & & 1277 & 32.4 & 11.6 & \\
\hline Systolic blood pressure, BP (mmHg) & 2543 & 127.8 & 16.5 & & 1174 & 132.0 & 16.0 & & 1369 & 124.3 & 16.1 & \\
\hline Diastolic blood pressure, BP $(\mathrm{mmHg})$ & 2543 & 81.3 & 10.6 & & 1174 & 84.3 & 10.5 & & 1369 & 78.7 & 10.0 & \\
\hline Lower limb extension power, LEP (watt/kg) & 319 & 2.9 & 1.0 & & 136 & 3.5 & 1.0 & & 183 & 2.5 & 0.8 & \\
\hline Handgrip strength, HGS $(\mathrm{kg})$ & 2536 & 40.8 & 11.2 & & 1172 & 50.6 & 7.5 & & 1364 & 32.4 & 5.6 & \\
\hline
\end{tabular}

a Alcohol consumption defined by whether Danish weekly drinking limits ( $\leq 14$ drinks for men; $\leq 7$ drinks for women) were met or exceeded.

${ }^{b}$ MVPA defined by whether Danish recommendations of $\geq 3.5$ hours/week of MVPA were met or not.

sitting. Neither work- nor leisure-time sitting was associated with diastolic BP (figure 1C). When adjusting for waist circumference, the association between leisure-time sitting and systolic BP remained significant $(\mathrm{P}=0.0298)$ (data not shown). Adjusting for occupational stress did not change the associations with systolic or diastolic BP (data not shown). Neither work- nor leisure-time sitting were associated with LEP (figure 1D), whereas leisuretime sitting was significantly, detrimentally associated with HGS (figure E.1-2) $(\mathrm{P}<0.05)$ among adults $<50$ years (figure E.1) but not $\geq 50$ years (figure E.2).

Adjustment for leisure-time sitting was performed in analyses with work-time sitting and vice-versa to account for possible interrelation between the two domains. In analysis with work-time sitting, associations attenuated slightly after adjustment for leisure-time sitting, otherwise little changed (data not shown). To account for outliers, we excluded participants with $<0.5$ hours/day leisure-time sitting $>8$ hours/day, and work-time sitting $>9$ hours/day; results remained unchanged. Furthermore, possible confounding by seasonal variation was investigated, but this did not change the direction or magnitude of the associations (data not shown).

\section{Discussion}

In the present study, we investigated the associations of work- and leisure-time sitting with key markers of cardiorespiratory and muscular fitness in a populationbased study of working adults. We found significant 
A

Estimated $\mathrm{VO}_{2} \mathrm{Max}(\mathrm{ml} / \mathrm{kg} / \mathrm{min})$

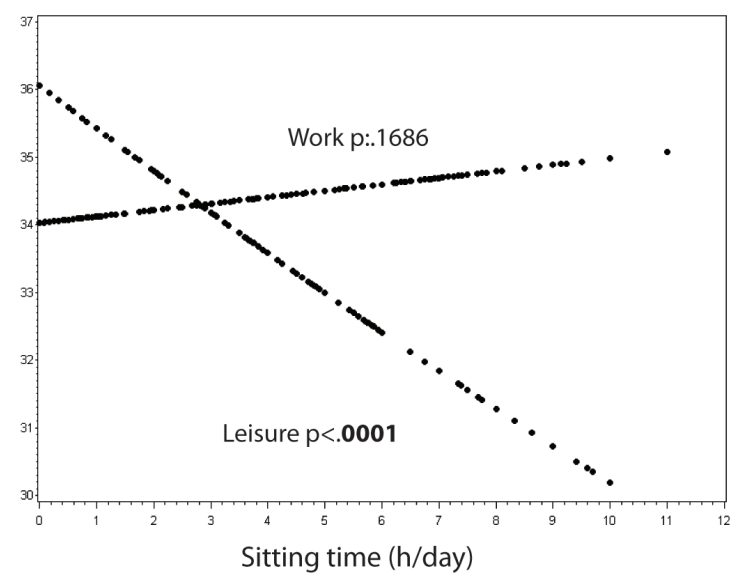

C

Diastolic BP ( $\mathrm{mmHg})$

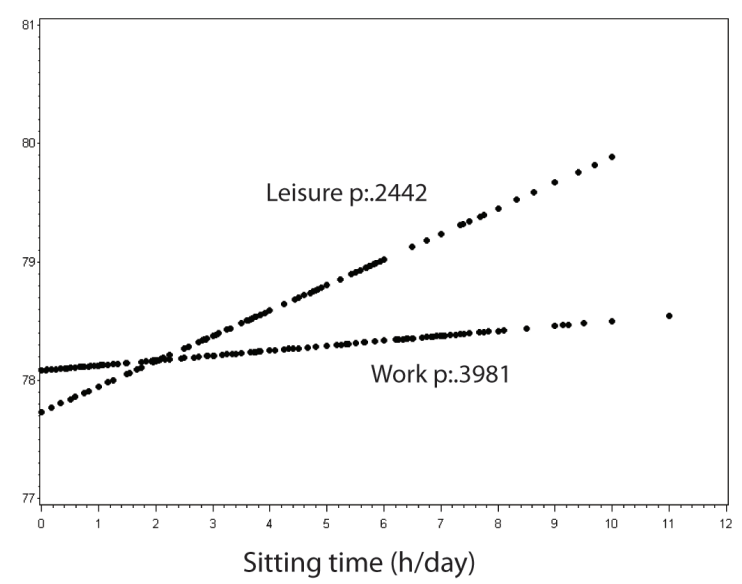

E.1 ( $<50$ years)

Handgrip strength, HGS (kg)

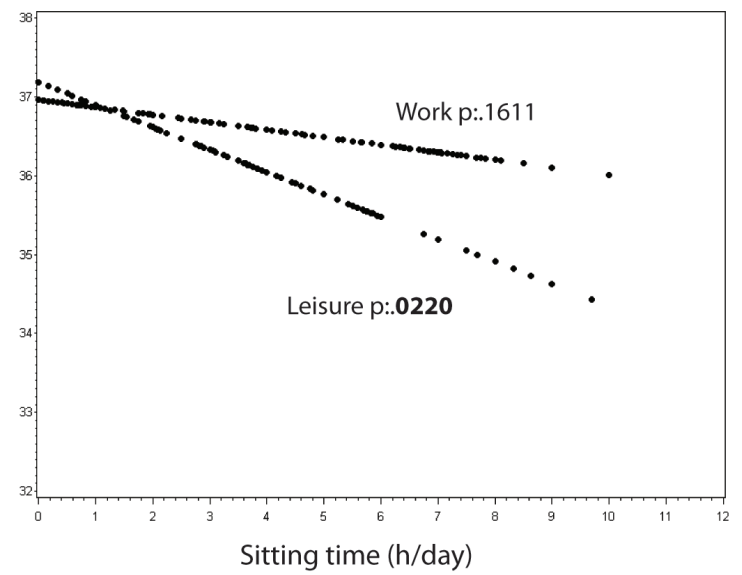

B

Systolic BP (mmHg)

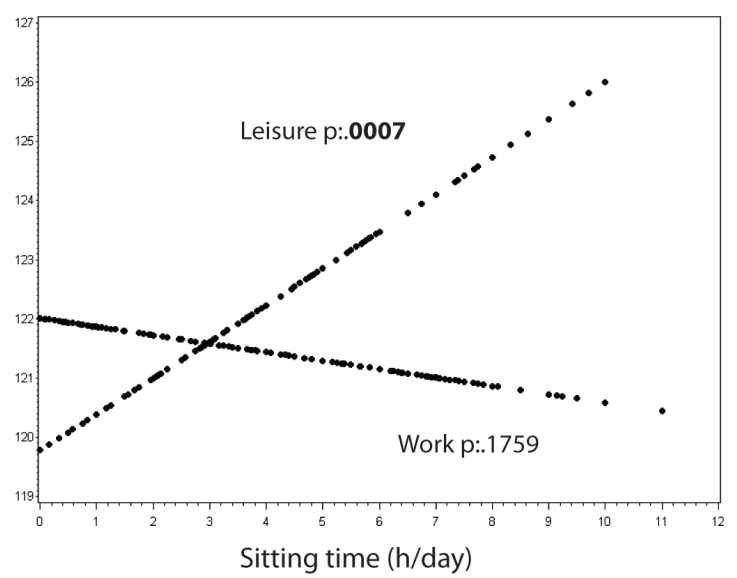

D

Lower limb extension power, LEP (watt/kg)

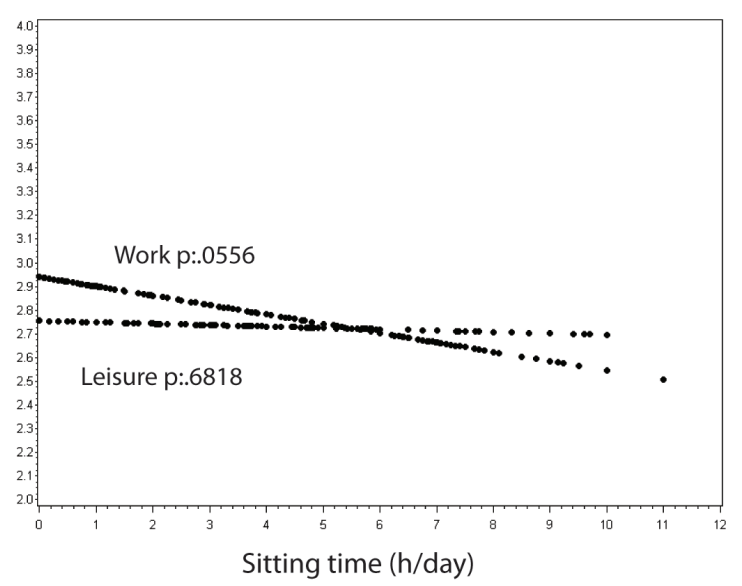

E.2 ( $\geq 50$ years)

Handgrip strength, HGS (kg)

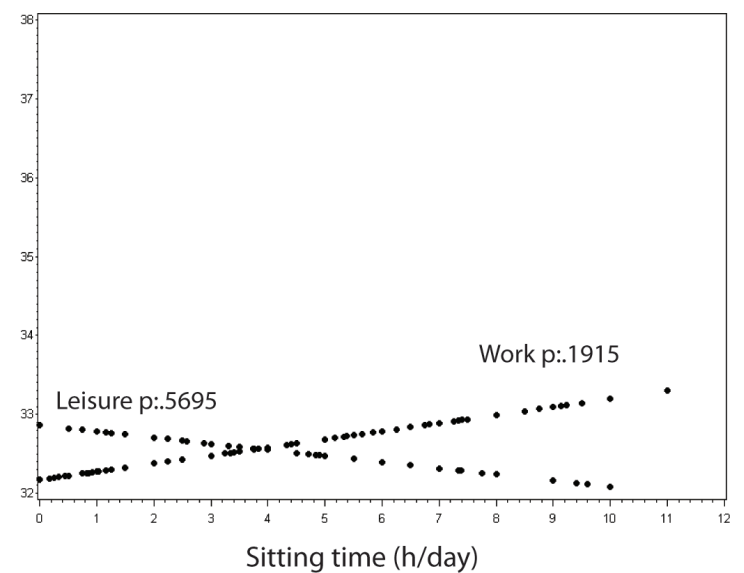

Figure 1. Regression plots for work and leisure-time sitting. A: Associations with estimated $\mathrm{VO}_{2} \mathrm{Max}(\mathrm{N}=2310)$. B: Associations with systolic blood pressure $(B P)(N=2249)$. C: Associations with diastolic BP $(N=2249)$. D: Associations with lower-limb extension power $(\mathrm{LEP})(\mathrm{N}=316)$. E: Associations with handgrip strength (HGS) for adults $<50$ years $(E .1)(N=1464)$ and $\geq 50$ years $(E .2)(N=1014)$. Plots are adjusted for sex, age, education, occupational physical activity, and moderate to vigorous physical activity (MVPA). Further adjustment for smoking in $\mathrm{VO}_{2} \mathrm{Max}_{\text {(A) }}$, smoking, alcohol consumption, diet in $\mathrm{BP}(\mathrm{B}, \mathrm{C})$, height in HGS (E1, E2). 
detrimental associations of leisure-time sitting with $\mathrm{VO}_{2} \mathrm{Max}$, systolic $\mathrm{BP}$, and HGS among adults $<50$ years. We did not find any statistical significant associations with sitting at work. Findings converge to one main suggestion: sitting at work is less harmful than sitting during leisure time for cardiorespiratory and muscular fitness among adults.

The observed associations between leisure-time sitting and $\mathrm{VO}_{2} \mathrm{Max}$, systolic $\mathrm{BP}$ and HGS are comparable to what others have found. To our knowledge the relationship between sedentary behavior and $\mathrm{VO}_{2} \mathrm{Max}$ has not been specifically investigated among adults. However, several studies among children and youth have reported detrimental associations between sitting time and $\mathrm{VO}_{2} \operatorname{Max}(11,29)$. $\mathrm{VO}_{2} \mathrm{Max}$ is drastically reduced among healthy adults confined to bed rest (30), however, bed rest and everyday sedentary behaviors constitute two different situations that may not have the same physiological implications (29). Nonetheless, our results support an adverse relationship of sitting time with $\mathrm{VO}_{2} \mathrm{Max}$ also among adults, yet only for leisure-time sitting.

Our findings regarding systolic BP add to the mounting evidence of an association with leisure-time sitting; whilst few have considered other sitting domains (31). The lack of association with work-time sitting corresponds to other studies $(15,31)$. Work is a potential source of everyday stress, correlated with physiological responses including high BP (32). Therefore, we adjusted BP models as a proxy for occupational stress. Results were unchanged which could indicate that sedentary occupation may not have a negative influence on BP. The association between leisure-time sitting and systolic BP persisted even after adjustment for waist circumference, unlike findings of other studies (15).

Associations between sedentary behavior and muscular fitness were confined to HGS. This is perhaps not surprising, as our sample size including LEP data $(\mathrm{N}=319)$ could limit the ability to discern associations between sitting time and LEP. LEP has been identified as a method to assess explosive muscle power (33), and prolonged sitting induces a lack of contraction of lower limb muscles (34). As regards handgrip, results showed that leisure-time sitting was associated with a decreased HGS, but only among adults $<50$ years, which was rather surprising since HGS has been described as an overall muscle performance test, particularly useful among the middle-aged and elderly $(26,27)$. As the study is restricted to a working population, including fit elderly subjects, our results could indicate a "healthy worker bias". However, our findings (ie, sitting during leisure-time but not at work is associated with HGS) are comparable to those of Hamer et al (13), which showed adverse effects of leisure-time TV-viewing on HGS among older adults, while Internet usage was positively associated with HGS (13).
Overall, the results of the present study indicate that the manner in which sitting time is accrued is important for associations of sitting time with cardiorespiratory and muscular fitness. This is in line with mounting evidence for a differential effect of different domains of sitting $(14,16,35)$ and suggests that sitting during work and leisure time involve different types of sitting [eg, the modality of sitting (posture, duration and number of breaks)], attributes of the environment, and the social contexts (36). Results may equally give claim to another interpretation: they might reflect residual socioeconomic confounding, eg, is a truck driver who sits a lot comparable to a desk-based officer? Hence, it may be that something else is driving the associations, although we adjusted for years of education and occupational physical activity. Experimental studies have shown that prolonged sitting leads to metabolic abnormalities via suppressed action of muscle lipoprotein lipase and insulin, supporting a unique "inactivity physiology" paradigm (37-39) and hence, we believe that sedentary behaviors may (also) influence health via pathways that are independent of social class.

The study's strengths includes the information on distinctive sedentary behaviors. Leisure-time was not limited to TV-viewing. Also, we were able to adjust for significant lifestyle and socioeconomic characteristics; occupational physical activity is of importance. Finally, the coverage of the cohort increases the applicability of the findings to the Danish population, although restricted to those in work, as imposed by our study's aim.

The study's limitations should also be noted. Sitting time is self-reported and hence relies on the participant's ability to remember and identify sitting time, so it can be prone to (un)conscious misreporting. This could particularly be the case with the reporting of sitting at work. Participants might report their daily working hours as work-time sitting, and thus overestimate their sitting and not reflect differences in breaks between work- and leisure-time sitting. Likewise participants might underestimate their leisure-time sitting, as it can be difficult to recall. That said, it is unfeasible to identify the domains in which sitting occurs from objective measurements alone. Finally, a major limitation of the study is its cross-sectional design; we cannot rule out the possibility of reverse causality, namely, poor cardiorespiratory and muscular fitness, due to any reason, make people sit more.

\section{Concluding remarks}

In conclusion, we observed differential associations of work- and leisure-time sitting with key markers of cardiorespiratory and muscular fitness among working adult men and women. Many studies have focused on a single domain of sitting time or have only considered 
the sum of sedentary behaviors. This may blur the distinction in the relationships with different sedentary behaviors. Workplace strategies to reduce sitting are today being formulated with an expected reduction in health risk factors. Hitherto, evidence on the impact on cardiorespiratory and muscular fitness is truly limited. Given the emerging focus on reducing the amount of time spent sitting at work, this identified discrepancy between work- and leisure-time sitting was rather surprising. Further investigation is warranted to elucidate the pathways through which different sedentary behaviors leads to adverse health effects.

\section{Competing interests}

The authors declare no competing interests.

\section{Funding}

The Health Insurance Foundation (Helsefonden), grant number 2013B228, supported this work. The funders had no role in study design, data collection and analysis, decision to publish, or preparation of the manuscript.

\section{References}

1. VicHealth. Reducing prolonged sitting in the workplace. An evidence review: summary report. VicHealth. 2012.

2. Roffey DM, Wai EK, Bishop P, Kwon BK, Dagenais S. Causal assessment of occupational sitting and low back pain: results of a systemtatic review. Spine J. 2010;10(3):252-61. http:// dx.doi.org/10.1016/j.spinee.2009.12.005.

3. Tremblay M, LeBlanc AG, Kho ME, Saunders TJ, Larouche R, Colley RC et al. Systematic review of sedentary behaviour and health indicators in school-aged children and youth. IJBNPA. 2011;8:98.

4. Proper KI, Singh AS, van Mechelen W, Chinapaw MJ. Sedentary behaviors and health outcomes among adults. A systematic review of prospective studies. Am J Prev Med. 2011; 40:174-82. http://dx.doi.org/10.1016/j.amepre.2010.10.015.

5. Thorp AA, Owen N, Neuhaus M, Dunstan DW. Sedentary behaviors and subsequent health outcomes in adults. A systematic review of longitudinal studies 1996-2011. Am J Prev Med. 2011;41(2):207-15. http://dx.doi.org/10.1016/j. amepre.2011.05.004.

6. Pate RR, O'Neill JR, Lobelo F. The evolving definition of sedentary. Exerc Sport Sci Rev. 2008;36(4):173-8. http:// dx.doi.org/10.1097/JES.0b013e3181877d1a.

7. Sedentary Behaviour Research Network. Letter to the Editor: Standardized use of the terms "sedentary" and "sedentary behaviours". Appl Physiol Nutr Metab. 2012;37:540-2. http:// dx.doi.org/10.1139/h2012-024.

8. Lee D, Artero EG,2 Sui X, Blair SN. Mortality trends in the general population: the importance of cardiorespiratory fitness. J Psychopharmacol. 2010;24(4 supplement):27-35.

9. McCartney N, Phillips S. Physical activity, muscular fitness, and health. In: Bouchard C, Blair SN, Haskell WL, eds. Physical Activity and Health. Champaign, IL. Human Kinetics. 2007:231-57.

10. Kell RT, Bell G, Quinney A. Musculoskeletal fitness, health outcomes and quality of life. Sports Med. 2001;31(12):86373. http://dx.doi.org/10.2165/00007256-200131120-00003.

11. Tremblay M, LeBlanc AG, Kho ME, Saunders TJ, Larouche R, Colley RC et al. Systematic review of sedentary behaviour and health indicators in school-aged children and youth. IJBNPA. 2011;8:98

12. Paalanne NP, Korpelainen RI, Taimela SP, Auvinen JP, Tammelin TH, Hietikko TM et al. Muscular fitness in relation to physical activity and television viewing among young adults. Med Sci Sports Exerc. 2009;41(11):1997-2002. http:// dx.doi.org/10.1249/MSS.0b013e3181a7f3a6.

13. Hamer M, Stamatakis E. Screen-Based Sedentary Behavior, Physical Activity, and Muscle Strength in the English Longitudinal Study of Ageing. PLoS ONE. 2013;8(6):e66222. http://dx.doi.org/10.1371/journal.pone.0066222.

14. Saidj M, Jørgensen T, Jacobsen RK, Linneberg A, Aadahl M. Separate and joint associations of occupational and leisuretime sitting with cardio-metabolic risk factors in working adults: A cross-sectional study. PLoS ONE. 2013;8(8):e70213. http://dx.doi.org/10.1371/journal.pone.0070213.

15. Pereira SMP, Ki M, Power C. Sedentary behavior and biomarkers for cardiovascular disease and diabetes in midlife: the role of television-viewing and sitting at work. PLoS ONE. 2012;7(2):e31132. http://dx.doi.org/10.1371/journal. pone. 0031132 .

16. Rhodes RE, Mark RS, Temmel CP. Adult sedentary behavior: a systematic review. Am J Prev Med. 2012;42(3):e3-28. http:// dx.doi.org/10.1016/j.amepre.2011.10.020.

17. Holtermann A, Hansen JV, Burr H, Søgaard K, Sjøgaard G. The health paradox of occupational and leisure-time physical activity. Br J Sports Med. 2012;46:291-5. http://dx.doi. org/10.1136/bjsm.2010.079582.

18. Thuesen B, Cequeira C, Aadahl M, Ebstrup JF, Toft U, Thyssen JP. Cohort Profile: The Health2006 cohort, Research Centre for Prevention and Health. Int J Epidemiol. 2014;43(2):568-75. http://dx.doi.org/10.1093/ije/dyt009.

19. Andersen LG, Groenvold M, Jørgensen T, Aadahl M. Construct Validity of a revised Physical Activity Scale and testing by cognitive interviewing. Scand J Pub Health. 2010;38(7):70714. http://dx.doi.org/10.1177/1403494810380099.

20. Aadahl M \& Jørgensen T. Validation of a new self-report instrument for measuring physical activity. Med Sci Sports Exerc. 2003;35(7):1196-202. http://dx.doi.org/10.1249/01. MSS.0000074446.02192.14.

21. Aadahl M, Kjær M, Kristensen JH, Mollerup B, Jørgensen T. Self-reported physical activity compared with maximal oxygen uptake in adults. Eur J Cardiovasc Prev Rehabil. 2007;14(3):422-8. http://dx.doi.org/10.1097/ HJR.0b013e3280128d00. 
22. Aadahl M, Zacho M, Linneberg A, Thuesen BH, Jørgensen T. Comparison of the Danish step test and the watt-max test for estimation of maximal oxygen uptake: the Health2008 study. Eur J Prev Cardiol. 2013;20(6):1088-94. http://dx.doi. org/10.1177/2047487312462825.

23. Aadahl M, Beyer N, Linneberg A, Thuesen BH, Jørgensen T. Grip strength and lower limb extension power in 19-72 year-old Danish men and women: the Health2006 study. BMJ Open. 2011;1:e00192. http://dx.doi.org/10.1136/ bmjopen-2011-000192.

24. Roberts HC, Denison HJ, Martin HJ, Pater HP, Syddall H, Cooper $\mathrm{C}$, et al. A review of the measurement of grip strength in clinical and epidemiological studies: towards a standardized approach. Age Ageing. 2011;40:423-9. http://dx.doi. org/10.1093/ageing/afr051.

25. Bassey EJ, Short AH. A new method for measuring power output in a single leg extension: feasibility, reliability and validity. Eur J Appl Physiol Occup Physiol. 1990;60:385-90. http://dx.doi.org/10.1007/BF00713504.

26. Sasaki H, Kasagi F, Yamada M, Fujita S. Grip strength predicts cause-specific mortality in middle-aged and elderly persons. Am J Med. 2007;120:337-42. http://dx.doi.org/10.1016/j. amjmed.2006.04.018.

27. Bohannon RW. Hand-grip dynamometry predicts future outcomes in aging adults. J Geriatr Phys Ther. 2008;31:3-10. http://dx.doi.org/10.1519/00139143-200831010-00002.

28. Toft U, Kristoffersen LH, Lau C, Borch-Johnsen K, Jørgensen T. The Dietary Quality Score: validation and association with cardiovascular risk factors: the Inter99 study. Eur J Clin Nutr. 2007;61:270-8. http://dx.doi.org/10.1038/sj.ejcn.1602503.

29. Santos R, Mota J, Okely AD, Pratt M, Moreira C, Coelhoe-Silva MJ, et al. The independent associations of sedentary behaviour and physical activity on cardiorespiratory fitness. Br J Sports Med. 2013 Feb 14. [Epub ahead of print]. http:// dx.doi.org/10.1136/bjsports-2012-091610.

30. McGuire DK, Levine BD, Williamson JW, Snell PG, Blomqvist CG, Saltin B, et al. A 30-year follow-up of the Dallas Bedrest and Training Study: I. Effect of age on the cardiovascular response to exercise. Circulation. 2011;104(12):1350-7.
31. Pouliou T, KiM, Law C, Power C. Physical activity and sedentary behaviour at different life stages and adult blood pressure in the 1958 British cohort. J Hypertens. 2012;30(2):275-83. http:// dx.doi.org/10.1097/HJH.0b013e32834f1915.

32. Dimsdale JE. Psychological stress and cardiovascular disease. J Am Coll Cardiol. 2008; 51(13):1237-46. http://dx.doi. org/10.1016/j.jacc.2007.12.024.

33. Skelton DA, Kennedy J, Rutherford OM. Explosive power and asymmetry in leg muscle function in frequent fallers and non-fallers aged over 65. Age Ageing. 2002;31:119-25. http:// dx.doi.org/10.1093/ageing/31.2.119.

34. Thyfault JP, Booth FW. Lack of regular physical exercise or too much inactivity. Curr Opin Clin Nutr Metab Care. 2011;14(4):374-8. http://dx.doi.org/10.1097/ MCO.0b013e3283468e69.

35. Heinonen I, Helajärvi H, Pahkala K, Heinonen OJ, Hirvensalo M, Pälve K, et al. Sedentary behaviours and obesity in adults: the Cardiovascular Risk in Young Finns Study. BMJ Open. 2013;3:e002901. http://dx.doi.org/10.1136/ bmjopen-2013-002901.

36. Owen N, Salmon J, Koohsari MJ, Turrell G, Giles-Corti B. Sedentary behaviour and health: mapping environmental and social contexts to underpin chronic disease prevention. $\mathrm{Br}$ J Sports Med. 2014;48:174-77. http://dx.doi.org/10.1136/ bjsports-2013-093107.

37. Hamilton MT, Hamilton DG, Zderic TW. Role of low energy expenditure and sitting in obesity, metabolic syndrome, type 2 diabetes, and cardiovascular disease. Diabetes. 2007;56(11):2655-67. http://dx.doi.org/10.2337/db07-0882.

38. Stephens BR, Granados K, Zderic TW, Hamilton MT, Braun B. Effects of 1 day of inactivity on insulin action in healthy men and women: interaction with energy intake. Metabolism. 2011;60(7):941-9. http://dx.doi.org/10.1016/j. metabol.2010.08.014.

39. Bergouignan A, Rudwill F, Simon C, Blanc S. Physical inactivity as the culprit of metabolic inflexibility: evidence from bed-rest studies. Journal of Applied Physiology. 2011;111(4):1201-10. http://dx.doi.org/10.1152/japplphysiol.00698.2011.

Received for publication: 27 January 2014 